\title{
Uji Antioksidan Sediaan Stick Balm Ekstrak Daun Rhizophora Mucronata Dengan Metode Dpph
}

\author{
Maziyatul Faiqoh ${ }^{1 *}$, Tri Fitri Yana Utami ${ }^{2}$, Yuniariana Pertiwi ${ }^{3}$ \\ 1,2,3 Program Studi S1 Farmasi, STIKES Al-Irsyad Al-Islamiyyah Cilacap, Jawa Tengah, Indonesia \\ e-mail: ${ }^{1}$ maziyafaiq25@gmail.com, ${ }^{2}$ trifitriyana@ mail.ugm.ac.id, ${ }^{3}$ yuniaryana@yahoo.com
}

\begin{abstract}
ABSTRAK
Daun mangrove (Rhizophora mucronata) mengandung senyawa karotenoid yang merupakan senyawa poliena isoprenoid yang bersifat lipofilik, mudah diisomerisasi dan dioksidasi, menyerap cahaya, meredam oksigen, memblok reaksi radikal bebas dan dapat berikatan dengan permukaan hidrofobik. Tujuan dari penelitian ini adalah untuk mengetahui aktivitas antioksidan ekstrak metanol daun mangrove (Rhizophora mucronata) setelah dalam bentuk sediaan Stick balm. Metode ekstraksi dalam penelitian ini yaitu maserasi dan partisi. Hasil skrining fitokimia sebelum partisi ekstrak metanol daun mangrove (Rhizophora mucronata) mengandung alkaloid,flavonoid, steroid, terpenoid, saponin, dan tanin, sedangkan setelah partisi mengandung steroid, terpenoid, saponin, dan tanin. Hasil analisis panjang gelombang maksimal adalah $415 \mathrm{~nm}$. Sediaan Stick balm dilakukan evaluasi mutu fisik berupa uji homogenitas, uji suhu lebur, uji pH, dan uji stabilitas. Hasil pengujian menunukkan bahwa ketiga formula sediaan homogen, memiliki nilai suhu lebur $58^{\circ} \mathrm{C}$, memiliki nilai pH 5 dan stabil pada suhu $40^{\circ} \mathrm{C}$ dengan tidak menunjukkan adanya perubahan dari sisi organoleptis. Pengujian aktivitas antioksidan dilakukan dengan metode DPPH. Hasil nilai IC 50 yang diperoleh untuk formula 1, formula 2, dan formula 3 berturutturut adalah 57,40 ppm, 57,14 ppm,da 77,32 ppm. Hasil tersebut menunjukkan bahwa ketiga formula termasuk kedalam kategori antioksidan kuat. Sediaan Stick balm dilakukan uji iritasi dengan hasil bahwa sediaan tidak menimbulkan iritasi.
\end{abstract}

Kata Kunci: Ekstrak metanol daun mangrove, Stick balm, Antioksidan

\begin{abstract}
Mangrove leaves (Rhizophora mucronata) contain carotenoid compounds which are lipophilic polyene isoprenoid compounds, easily isomerized and oxidized, absorb light, absorb oxygen, block free radical reactions and can bind to hydrophobic surfaces. The purpose of this study was to determine the antioxidant activity of mangrove leaf (Rhizophora mucronata) methanol extracts after being in the form of Stick balm. Extraction methods in this study are maceration and partitioning. Phytochemical screening results before partitioning of mangrove leaves (Rhizophora mucronata) methanol extracts contain alkaloids, flavonoids, steroids, terpenoids, saponins, and tannins, whereas after partitioning they contain steroids, terpenoids, saponins, and tannins. The results of the analysis of the maximum wavelength is 415 $n m$. Stick balm preparations were evaluated for physical quality in the form of homogeneity tests, melting temperature tests, $\mathrm{pH}$ tests, and stability tests. The test results show that all three formulas are homogeneous, have a melting temperature at $580 \mathrm{C}$, have a $\mathrm{pH}$ value of 5 and are stable at $40 \mathrm{C}$ with no change in organoleptic side. Testing the antioxidant activity was carried out by the DPPH method. IC50 values obtained for formula 1, formula 2, and formula 3 are $57.40 \mathrm{ppm}$, $57.14 \mathrm{ppm}$, and $77.32 \mathrm{ppm}$ respectively. These results indicate that all three formulas are included in the category of strong antioxidants. Stick balm preparation was tested for irritation with the result that the preparation did not cause irritation.
\end{abstract}

Keyword: Mangrove leaf methanol extract, Stick balm, antioxidant

\section{PENDAHULUAN}

Radikal bebas adalah suatu atom atau molekul yang tidak berpasangan. Elektron yang tidak berpasangan tersebut menyebabkan radikal bebas sangat reaktif yang kemudian akan menangkap atau mengambil elektron dari senyawa lain yang mengakibatkan terjadinya stress oksidatif. Akibatnya kemampuan darah membawa oksigen akan berkurang sehingga berakibat pada apoptosis sel, dan apabila terpapar terus menerus dapat menyebabkan peningkatan risiko penyakit. Tubuh memerlukan antioksidan sebagai penetral stress oksidatif yang disebabkan oleh 
radikal bebas. Antioksidan sangat diperlukan oleh tubuh untuk mengatasi dan mencegah stres oksidatif[1].

Antioksidan didefinisikan sebagai inhibitor yang bekerja menghambat oksidasi dengan cara bereaksi dengan radikal bebas reaktif yang membentuk radikal bebas tidak reaktif yang tidak stabil[2]. Antioksidan dapat diproduksi secara sintetik maupun diperoleh secara alami. Antioksidan alami dapat diperoleh dari berbagai jenis tanaman seperti tanaman mangrove jenis Rhizophora mucronata.

Daun mangrove Rhizopora mucronata mengandung 2-(2etoksi etanol, kau-16-ena dan benzophenon, senyawa fenolik golongan flavonoid, asam fenolat, tannin dihidroflavonol, asam kafeat, asam vanilat, asam p-hidroksi benzoate, tanin, alkaloid, kumarin, flavonoid, fenol dan polifenol, quinon, resin, saponin, fitosterol, xanthoprotin, pigmen (klorofil, karotenoid) dan gula[3]. Senyawa karotenoid ini yang menjadi target senyawa peneliti untuk dikembangkan menjadi sebuah sediaan Stick balm yang berfungsi sebagai antiaging. Hal ini didasari oleh penelitian [4] bahwa karotenoid memiliki aktivitas pembersihan radikal bebas, penghambatan aktivitas elastase dan ekspresi MMP-1 yang berperan dalam proses penghambatan terjadinya aging. Paramereter pengujian yang digunakan yaitu dengan mengetahui aktivitas antioksidan dari sediaan Stick balm menggunakan metode DPPH sehingga dapat meredam radikal bebas dan mencegah terjadinya aging.

Tujuan penelitian ini adalah mengetahui aktivitas antioksidan sediaan Stick balm ekstrak metanol daun mangrove (Rhizophora mucronata) dengan metode DPPH. Metode DPPH dipilih karena metode ini merupakan metode pengukuran yang efektif dan cepat dalam memperkirakan aktivitas antioksidan.

\section{METODE PENELITIAN}

\subsection{Alat dan Bahan}

Alat yang digunakan dalam penelitian ini diantaranya adalah jas lab, sarung tangan (Sensi Gloves $^{\circledR}$ ), masker (Sensi Mask ${ }^{\circledR}$ ), kain flanel, aluminium foil, alat-alat gelas (Pyrex), kertas pH, kertas saring, cawan porselen, waterbath, neraca analisis digital Ohauss (Pioneer ${ }^{T M}$ ), corong pisah, kuvet, dan Spektrofotometri UV-Vis (Spectrumlab 22 PC).

Bahan yang digunakan dalam penelitian ini adalah metanol (teknis), daun mangrove, dietil eter, $\mathrm{NaCl}$, akuades, $\mathrm{DPPH}, \mathrm{HCl}, \mathrm{H} 2 \mathrm{SO} 4$, kloroform, asetat anhidrat, logam $\mathrm{Mg}$, pereaksi Dragendorf, $\mathrm{FeCl} 3$, Kelinci (Oryctalagus cuniculus), n-hexana, lilin lebah (beeswax), minyak jarak, Tween 80 , vaseline, lemak coklat, madu, dan metil paraben.

\subsection{Prosedur Penelitian}

\subsubsection{Preparasi Sampel}

Sampel daun mangrove (Rhizopora mucranata) dicuci terlebih dahulu untuk menghilangkan kotoran yang menempel, kemudian dilakukan pengeringan daun. Daun yang sudah kering dipotong-potong menjadi ukuran yang lebih kecil. Daun yang telah dipotong selanjutnya dikeringkan di dalam lemari pengering. Daun yang telah kering sempurna kemudian dihaluskan menggunakan blender untuk memperkecil ukuran partikel, sehingga luas permukaannya menjadi besar[5].

\subsubsection{Determinasi Daun Mangrove}

Determinasi daun mangrove dilakukan dengan menggunakan metode studi referensi. Metode ini dilakukan dengan cara membandingkan gambar sampel dengan referensi yang sudah ada.

\subsubsection{Pembuatan Ekstrak Metanol Daun Mangrove (Rhizophora mucronata)}

Sampel diekstraksi dengan menggunakan metode maserasi. Pelarut yang digunakan adalah metanol (polar) dengan perbandingan $1: 4$, kemudian dilakukan remaserasi. Ekstraksi yang dilakukan dengan menggunakan 300 gram daun mangrove dalam 1,2 L pelarut metanol. 
Proses maserasi dilakukan salama 3x24 jam dan dilakukan remaserasi dengan durasi yang sama. Hasil maserasi kemudian di uapkan dengan menggunakan waterbath pada suhu $65^{\circ} \mathrm{C}$ agar diperoleh ekstrak metanol kental. Setelah pekat ekstrak metanol selanjutnya ditambah larutan $\mathrm{NaCl}$ jenuh lalu diekstraksi cair-cair (partisi) dengan menggunakan pelarut dietil eter dengan perbandingan $1: 1$, kemudian diuapkan pada suhu $34,6^{\circ} \mathrm{C}[6]$.

\subsubsection{Skrining Fitokimia}

a. Uji Flavonoid

Sejumlah sampel diambil dan dimasukkan kedalam tabung reaksi. Kemudian ditambahkan 1-2 butir logam magnesium dan beberapa tetes HCl. Sampel positif mengandung flavonoid jika terbentuk warna orange hingga merah[7].

b. Uji Alkaloid

Sejumlah sampel dilarutkan dalam beberapa tetes asam sulfat $2 \mathrm{~N}$. Kemudian ditambahkan beberapa tetes pereaksi dragendorf. Hasil positif ditunjukkan dengan terbentuknya endapan warna merah jingga[8].

c. Uji Steroid dan Terpenoid

Sejumlah sampel dilarutkan dalam $2 \mathrm{~mL}$ kloroform dalam tabng reaksi kering, kemudian ditambahkan 10 tetes anhidrat asetat dan 3 tetes asam sulfat pekat. Adanya senyawa terpenoid ditujukan dengan terbentuknya warna merah atau ungu dan senyawa steroid ditandai dengan terbentuknya warna hijau $[8,9]$.

d. Uji Saponin

Sedikit ekstrak dimasukkan ke dalam tabung reaksi dan ditambahkan $10 \mathrm{~mL}$ akuades panas dan dikocok kuat-kuat selama 10 detik, jika menghasilkan busa yang stabil setinggi 1-10 cm maka menunjukkan adanya senyawa saponin[10].

e. Uji Tanin

Sampel sebanyak 2 gram dilarutkan dengan air panas sebanyak $5 \mathrm{~mL}$ kemudian disaring dan dipindahkan ke tabung lain. Kemudian ditambahkan $\mathrm{FeCl}_{3}$ sebanyak 2 tetes. Sampel positif mengandung tanin apabila mengalami perubahan warna menjadi hijau kehitaman[7].

\subsubsection{Analisis Panjang Gelombang Maksimal}

Analisis sampel daun mangrove (Rhizophora mucronata) dilakukan di Laboratorium Kimia Farmasi STIKES Al Irsyad Al Islamiyyah Cilacap. Analisis dilakukan menggunakan Spektrofotometri UV-Vis (Spectrumlab 22 PC) dalam pelarut n-heksana pada panjang gelombang 350-600 $\mathrm{nm}[6]$.

\subsubsection{Formulasi Sediaan Stick balm (Modifikasi dari Arinka dan Suhartiningsih, 2014)}

Tabel I. Formula Stick balm dengan variasi konsentrasi ekstrak

\begin{tabular}{llll}
\hline \multirow{2}{*}{ Komponen } & \multicolumn{3}{c}{ Formula dengan variasi ekstrak } \\
\cline { 2 - 4 } & Formula 1 & Formula 2 & Formula 3 \\
\hline Ekstrak & 0,25 gram & 0,5 gram & 0,75 gram \\
Lilin Lebah (Beeswax) & 3,79 gram & 3,79 gram & 3,79 gram \\
Lemak coklat & 0,3 gram & 0,3 gram & 0,3 gram \\
Vaseline & 0,1 gram & 0,1 gram & 0,1 gram \\
Madu & 0,3 gram & 0,3 gram & 0,3 gram \\
Minyak Jarak & 2,5 gram & 2,5 gram & 2,5 gram \\
Tween 80 & 2,5 gram & 2,5 gram & 2,5 gram \\
Metil Paraben & 0,01 gram & 0,01 gram & 0,01 gram \\
\hline
\end{tabular}

\subsubsection{Evaluasi Mutu Fisik}

Parameter mutu fisik sediaan dilihat dari homogenitas, suhu lebur, $\mathrm{pH}$ dan stabilitas sediaan.

\subsubsection{Uji Aktivitas Antioksidan}

Sampel Stick balm dengan berbagai konsentrasi (150, 200, 250, 300, 350 ppm) diambil sebanyak $2 \mathrm{~mL}$ dimasukkan ke tabung reaksi yang sudah dibungkus alumunium foil kemudian ditambah $1 \mathrm{ml}$ larutan DPPH 0,004\%. Larutan dikocok sampai homogen dan 
dibiarkan selama 30 menit dalam suhu ruang tanpa cahaya. Absorbansi diukur pada panjang gelombang $517 \mathrm{~nm}$ menggunakan spektrofotometer UV-Vis[7].

\subsubsection{Uji Iritasi}

Uji iritasi dilakukan secara in vivo pada 3 ekor kelinci. Uji iritasi dilakukan dengan mencukur bulu pada punggung kelinci sampai bersih. Setelah itu, punggung hewan coba dibagi menjadi 3 bagian berbentuk bujur sangkar dengan ukuran masing-masing 1x1 inchi. Sebelum dioleskan bahan uji, kulit kelinci dibersihkan menggunakan kapas yang dibasahi akuades. Kulit kelinci diolesi bahan uji kemudian ditutup dengan menggunakan kassa dan diplester selama 24 jam. Setelah itu hewan uji dikembalikan ke kandangnya. Hari selanjutnya pada jam yang sama, plester dibuka dan kulit hewan uji dibersihkan dengan akuades dari sisa bahan uji yang menempel. Gejala yang timbul diamati yaitu iritasi primer yang berupa edema dan eritema selama 24, 48 dan 72 jam.

Tabel II. Pengamatan Uji Iritasi (Draize, 1959 dalam Priani et al., 2020)

\begin{tabular}{|c|c|}
\hline Reaksi Kulit & Skor \\
\hline \multicolumn{2}{|l|}{ Edema } \\
\hline Tanpa edema & 0 \\
\hline Sangat sedikit edema & 1 \\
\hline Edema tapi berbatas jelas & 2 \\
\hline Edema sedang (tepi naik $\pm 1 \mathrm{~mm}$ ) & 3 \\
\hline Edema berat (tepi naik $> \pm 1 \mathrm{~mm}$ dan meluas & 4 \\
\hline \multicolumn{2}{|l|}{ Eritema } \\
\hline Tanpa eritema & 0 \\
\hline Sangat sedikit eritema & 1 \\
\hline Eritema tapi berbatas jelas & 2 \\
\hline Eritema sedang sampai berat & 3 \\
\hline Eritema berat (merah) sampai membentuk kerak & 4 \\
\hline
\end{tabular}

Perhitungan derajat iritasi[11, 12]:

$\frac{\text { skor edema }(24+48+72 \text { jam })+\text { Skor eritema }(24+48+72 \text { jam })}{\text { jumlah kelinci }}$

Indeks iritasi yang diperoleh dibandingkan dengan skor indeks iritasi untuk mengetahui keparahan reaksi iritasi (Tabel 3.):

Tabel III. Penentuan Derajat Iritasi (Draize, 1959 dalam Priani et al., 2020)

\begin{tabular}{cc}
\hline Reaksi iritasi & Derajat iritasi \\
\hline Tidak mengiritasi & 0 \\
Sangat sedikit mengiritasi & $0,1-0,4$ \\
Sedikit mengiritasi & $0,41-1,9$ \\
Iritasi sedang & $2,0-4,9$ \\
Iritasi parah & $5,0-8,0$ \\
\hline
\end{tabular}

\section{HASIL DAN PEMBAHASAN}

\subsection{Preparasi Sampel}

Daun mangrove yang digunakan dalam penelitian ini diperoleh dari tempat Wisata Hutan Payau Cilacap, dengan bobot daun mangrove yang diterima yaitu $4 \mathrm{~kg}$.

\subsection{Determinasi Daun Mangrove}

Berdasarkan buku Panduan pengenalan mangrove di Indonesia karya Noor et al. (2006) dan buku Panduan Mangrove Estuari Perancak karya Sidik et al. (2018) maka dapat disimpulkan bahwa jenis tanaman mangrove yang diambil oleh peneliti sebagai subjek penelitian merupakan jenis Rhizophora mucronata[13, 14].

\subsection{Pembuatan Ekstrak Metanol Daun Mangrove (Rhizophora mucronata)}


Ekstrak daun mangrove diperoleh melalui dua proses ekstraksi yaitu ekstraksi pertama menggunakan metode maserasi dan dilanjutkan dengan menggunakan metode ekstraksi partisi. Hal ini dilakukan karena target senyawa yang ingin diperoleh dalam penelitian ini adalah senyawa karotenoid yang merupakan senyawa nonpolar. Persentase rendemen ekstrak metanol yang diperoleh pada proses maserasi adalah sebesar 22,39\%. Ekstrak metanol hasil maserasi ditambahkan dengan larutan $\mathrm{NaCl}$ jenuh lalu dipartisi dengan dietil eter dengan perbandingan $1: 1$, kemudian diuapkan hingga diperoleh ektrak kental. Persentase rendemen yang diperoleh adalah sebesar 10,16\%.

\subsection{Skrining Fitokimia}

Tabel IV. Hasil Analisis Fitokimia

\begin{tabular}{|c|c|c|c|c|}
\hline \multirow[t]{2}{*}{ Senyawa } & \multicolumn{2}{|c|}{ Sebelum partisi } & \multicolumn{2}{|c|}{ Sesudah partisi } \\
\hline & Hasil & Keterangan & Hasil & Keterangan \\
\hline Flavonoid & Positif & Terbentuk warna orange & Negatif & Tidak terbentuk warna \\
\hline Alkaloid & Positif & Ada endapan & Negatif & Tidak ada endapan \\
\hline $\begin{array}{l}\text { Steroid dan } \\
\text { Terpenoid }\end{array}$ & Positif & $\begin{array}{l}\text { Terbentuk warna hijau } \\
\text { untuk steroid dan warna } \\
\text { merah untuk terpenoid }\end{array}$ & Positif & $\begin{array}{l}\text { Terbentuk warna hijau } \\
\text { untuk steroid dan warna } \\
\text { merah untuk terpenoid }\end{array}$ \\
\hline Saponin & Positif & Terdapat busa & Positif & Terdapat busa \\
\hline Tanin & Positif & $\begin{array}{l}\text { Terjadi perubahan warna } \\
\text { menjadi hijau kehitaman }\end{array}$ & Positif & $\begin{array}{l}\text { Terjadi perubahan } \\
\text { warna menjadi hijau } \\
\text { kehitaman }\end{array}$ \\
\hline
\end{tabular}

\subsection{Analisis Panjang Gelombang Maksimal}

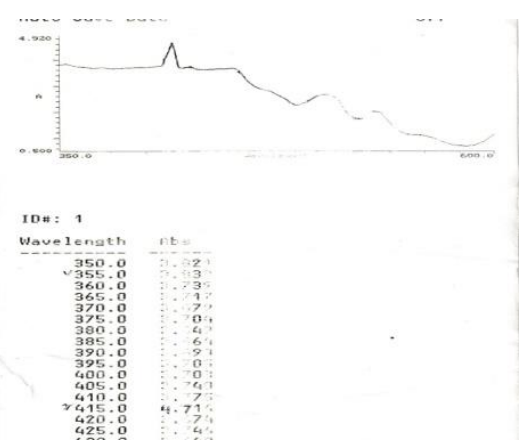

\section{Gambar 1. Hasil Pengukuran panjang gelombang maksimal}

Data pengukuran panjang gelombang maksimal $\left(\lambda_{\max }\right)$ ekstrak daun mangrove dengan menggunakan spektroskopi UV-Vis dengan pelarut n-heksana adalah $415 \mathrm{~nm}$. Hasil analisis tersebut seperti yang ditunjukkan pada Gambar adalah khas untuk senyawa karotenoid yang menyerap sinar UV pada daerah 300-600 nm, terdiri atas sebuah puncak utama. Berdasarkan buku A Guide To Carotenoids Analysis in Food karya Delia B. Rodriguez-Amaya, Ph.D (2001) jenis karotenoid yang memiliki panjang gelombang maksimal pada $415 \mathrm{~nm}$ adalah neoxanthin[15].

\subsection{Formulasi Sediaan Stick balm}

Sediaan Stick balm dibuat 3 formulasi. Masing-masing sediaan dibuat sebanyak 10 gram. Ekstrak daun mangrove berperan sebagai zat aktif yang berfungsi sebagai antioksidan. Berdasarkan hasil penelitian semakin banyak konsentrasi ekstrak yang ditambahkan semakin pekat warna sediaan yang dihasilkan.

\subsection{Evaluasi Mutu Fisik}

Hasil evaluasi mutu fisik menunjukkan bahwa ketiga formula sediaan homogen, memiliki nilai suhu lebur $58^{\circ} \mathrm{C}$, memiliki nilai $\mathrm{pH} 5$ dan stabil pada suhu $40^{\circ} \mathrm{C}$ dengan tidak menunjukkan adanya perubahan dari sisi organoleptis.

\subsection{Uji Aktivitas Antioksidan}


Tabel V. Hasil pengukuran $\mathrm{IC}_{50}$

\begin{tabular}{|c|c|c|c|c|}
\hline Sampel & Konsentrasi & Absorbansi & $\%$ inhibisi & $\mathrm{IC}_{50}(\mathrm{ppm})$ \\
\hline \multirow{5}{*}{ Formula 1} & 150 & 0,815 & 43,48 & \multirow{5}{*}{57,40} \\
\hline & 200 & 0,796 & 40,14 & \\
\hline & 250 & 0,737 & 29,75 & \\
\hline & 300 & 0,770 & 35,56 & \\
\hline & 350 & 0,718 & 26,41 & \\
\hline \multirow{5}{*}{ Formula 2} & 150 & 0,776 & 36,62 & \multirow{5}{*}{57,14} \\
\hline & 200 & 0,735 & 26,40 & \\
\hline & 250 & 0,659 & 16,02 & \\
\hline & 300 & 0,641 & 12,85 & \\
\hline & 350 & 0,604 & 6,34 & \\
\hline \multirow{5}{*}{ Formula 3} & 150 & 0,716 & 26,06 & \multirow{5}{*}{77,32} \\
\hline & 200 & 0,664 & 16,90 & \\
\hline & 250 & 0,396 & 30,28 & \\
\hline & 300 & 0,646 & 13,73 & \\
\hline & 350 & 0,550 & 3,17 & \\
\hline \multirow{5}{*}{ Ekstrak } & 150 & 0,164 & 71,12 & \multirow{5}{*}{511,76} \\
\hline & 200 & 0,133 & 76,58 & \\
\hline & 250 & 0,128 & 77,46 & \\
\hline & 300 & 0,144 & 74,64 & \\
\hline & 350 & 0,109 & 80,81 & \\
\hline
\end{tabular}

Hasil nilai $\mathrm{IC}_{50}$ yang diperoleh pada masing-masing sampel dapat dilihat pada Tabel 5 . Hasil perolehan nilai $\mathrm{IC}_{50}$ terbaik ada pada formula 2 yaitu $57,14 \mathrm{ppm}$. Sedangkan untuk formula 1 dan formula 3 memiliki nilai IC $_{50}$ berturut-turut sebesar 57,40 ppm dan 77,32 ppm. Berdasarkan nilai $\mathrm{IC}_{50}$ tersebut dapat dikatakan bahwa aktivitas antioksidan pada formula 1,2 dan 3 termasuk kedalam antioksidan kuat. Hal ini diperkuat bahwa suatu senyawa dikatakan sebagai antioksidan sangat kuat apabila nilai $\mathrm{IC}_{50}$ dari senyawa tersebut kurang dari 50, kuat (50-100), sedang (100-150), dan lemah (150-200). Badarinath (2010) menegaskan bahwa semakin kecil nilai $\mathrm{IC}_{50}$ yang diperoleh maka semakin besar aktivitas antioksidannya[16].

Pengujian juga dilakukan terhadap ekstrak, hal ini dilakukan guna untuk memperkuat data yang telah ada. Hasil $\mathrm{IC}_{50}$ ekstrak yang diperoleh adalah sebesar 511,76 ppm. Hal ini berarti ekstrak daun mangrove memiliki aktivitas antioksidan yang sangat lemah. Hasil tersebut sangat berbeda apabila dibandingkan dengan hasil $\mathrm{IC}_{50}$ pada formula. Hal tersebut dapat terjadi karena adanya bahan lain dalam formula yang juga dapat berperan sebagai antioksidan seperti lemak kakao dan madu yang juga dapat berperan sebagai antioksidan, sehingga aktivitas antioksidan pada formula jauh lebih baik daripada ekstrak.

Hasil pengukuran antioksidan pada ekstrak berbeda dengan penelitian yang sudah terjadi sebelumnya, dimana ekstak metanol daun mangrove (Rhizophora mucronata) dapat meredam radikal bebas DPPH sebesar 113,41 ppm dan pada penelitian Bibi et al. (2019) memiliki nilai $\mathrm{IC}_{50}$ sebesar $47,39 \pm 0,43 \mathrm{ppm}[3,17]$. Hal ini dapat terjadi karena pada penelitian sebelumnya dalam ekstrak masih terkandung banyak senyawa yang berperan sebagai antioksidan yang kuat seperti flavonoid dan alkaloid dimana senyawa tersebut termasuk kedalam senyawa polar. Namun pada penelitian ini dilakukan ekstraksi kembali sehingga senyawa polar yang terkandung dalam ekstrak tidak termasuk dalam analisis peneliti, karena senyawa yang menjadi target antioksidan peneliti merupakan senyawa nonpolar yaitu karotenoid yang termasuk kedalam golongan senyawa terpenoid.

Terbatasnya jumlah senyawa yang berperan sebagai antioksidan dalam ekstrak ini yang dapat mengakibatkan rendahnya aktivitas antioksidan pada ekstrak daun mangrove (Rhizophora mucronata). Faktor lain yang dapat menyebabkan rendahnya nilai $\mathrm{IC}_{50}$ ekstrak 
juga karena terjadinya kerusakan antioksidan pada ekstrak bahwa kerusakan antioksidan didalam ekstrak dapat dipengaruhi oleh lamanya waktu kontak zat aktif dengan pelarut dan suhu yang semakin meningkat akibat pemanasan yang lama[16].

\subsection{Uji Iritasi}

Pengamatan uji iritasi dilakukan pada 24, 48 dan 72 jam setelah perlakuan. Selama 3 hari pengamatan tidak ditemukan adanya tanda kemerahan (eritema) dan bengkak (udema) pada 3 kelinci uji. Kelinci yang digunakan merupakan kelinci jantan jenis rex dengan rentan umur antara 4-10 bulan. Berdasarkan hasil pengamatan yang diperoleh mengenai terjadinya eritema dan udema terhadap kelinci serta perhitungan indeks iritasi primer tidak menunjukkan adanya iritasi pada kulit hewan uji. Hasil ini menandakan bahwa sediaan aman untuk digunakan pada kulit manusia. Meskipun pada dasarnya sensitifitas kulit hewan uji sedikit berbeda dengan manusia, namun dengan dilakukannya uji iritasi dapat mendukung data keamanan sediaan apabila digunakan pada kulit manusia.

\section{KESIMPULAN}

Berdasarkan penelitian yang telah dilakukan maka dapat ditarik kesimpulan bahwa sediaan Stick balm ekstrak metanol daun mangrove (Rhizophora mucronata) memiliki aktivitas antioksidan ketika diukur dengan medtode DPPH dengan nilai IC50 untuk formula 1, formula 2 dan formula 3 secara beturut-turut yaitu 57,40 ppm, 57,14 ppm dan 77,32 ppm yang berarti termasuk kedalam golongan antioksidan kuat.

\section{DAFTAR PUSTAKA}

[1] Berawi KN, Marini D, Fisiologi B, et al. Efektivitas Kulit Batang Bakau Minyak ( Rhizopora apiculata ) sebagai Antioksidan. J Agromedicine. 2018;5(1):412-417.

[2] Idris N. Penentuan Aktivitas Antioksidan Dari Buah Melon ( Cucumis melo Linn.) Secara Spektrofotometri UV-Vis. 2011.

[3] Ridlo A, Pramesti R, Supriyantini E, Soenardjo N. Aktivitas Antioksidan Ekstrak Daun Mangrove Rhizopora mucronata. Bul Oseanografi Mar. 2017;6(2):110-116.

[4] Garg C, Khurana P, Garg M. Molecular mechanisms of skin photoaging and plant inhibitors. Int J Green Pharm. 2017;11(2):217-232.

[5] Anggraini RR, Hendri M, Rozirwan. Potensi Larutan Bubuk Daun Mangrove Bruguiera gymnorrhiza Sebagai Pengawet Alami. Maspari J. 2018;10(1):51-62.

[6] Sulistyaningrum N. Isolasi dan Identifikasi Struktur Karotenoid dari Ekstrak Bayam Merah ( Amaranthus Tricolor L .). J Kefarmasian Indones. 2014;4(2):75-81.

[7] Paputungan Z, Wonggo D, Kaseger BE. Uji Fitokimia Dan Aktivitas Antioksidan Buah Mangrove Sonneratia alba Di Desa Nunuk Kecamatan Pinolosian Kabupaten Bolaang Mongondow Selatan. Media Teknol Has Perikan. 2017;5(3):190-195. doi:10.35800/mthp.5.3.2017.16866

[8] Priyanto RA. Aktivitas Antioksidan Dan Komponen Bioaktif Pada Buah Bakau (Rhizophora mucronata Lamk.). 2012.

[9] Ningsih DR, Zusfahair, Kartika D. Identifikasi Senyawa Metabolit Sekunder Serta Uji Aktivitas Ekstrak Daun Sirsak Sebagai Antibakteri. Molekul. 2016;11(1):101-111.

[10] Usman, Adi VZP. Potensi Antijamur Ekstrak Metanol Daun MangroveRhizophora mucronata Terhadap Jamur Candida Albicans dan Aspergillus Niger. J Kim Mulawarman. 2017;15(1):29-34.

[11] Priani SE, Abdilla SA, Suparman A. Pengembangan Sediaan Mikroemulsi Gel Antijerawat Mengandung Minyak Kulit Batang Kayu Manis ( Cinnamomum burmanni Nees ex Bl ). $J$ 
Ilm Farm Farmasyifa. 3(1):9-17. doi:10.29313/jiff.v3il.5464

[12] Rosida, Sidiq HBHF, Apriliyanti IP. Evaluasi Sifat Fisik Dan Uji Iritasi Gel Ekstrak Kulit Buah Pisang (Musa acuminata Colla). J Curr Pharm Sci. 2018;2(1):131-135.

[13] Noor YR, Khazali M, Suryadiputra N. Panduan Pegenalan Mangrove Di Indonesia. Bogor: PHKA/WI-IP; 2006.

[14] Sidik F, Kadarisman HP, Nusantara M, Widagti N. Buku Panduan Mangrove Estuari Perancak. Bali: BROL; 2018.

[15] Rodriguez-amaya DB. A Guide To Carotenoid Analysis in Food. Washington DC: International Life Science Institute (ILSI) Press; 2001.

[16] Tristantini D, Ismawati A, Pradana BT, Jonathan JG. Pengujian Aktivitas Antioksidan Menggunakan Metode DPPH pada Daun Tanjung ( Mimusops elengi L ). In: Prosiding Seminar Nasional Teknik Kimia "Kejuangan." Yogyakarta: UPN "Veteran” Yogyakarta; 2016:1-7.

[17] Bibi S, Fawzi M, Gokhan Z, et al. Ethnopharmacology, Phytochemistry, and Global Distribution of Mangroves-A Comprehensive Review. Mar Drugs. 2019;17(231):1-82. 